Bull. Chem. Soc. Ethiop. 2019, 33(2), 215-228.

ISSN 1011-3924

(c) 2019 Chemical Society of Ethiopia and The Authors

Printed in Ethiopia

DOI: https://dx.doi.org/10.4314/bcse.v33i2.3

\title{
SENSITIVE ELECTROCHEMICAL DETERMINATION OF ETHAMBUTOL IN PHARMACEUTICAL FORMULATION AND HUMAN URINE AT NICKEL NANOPARTICLES/ELECTROCHEMICALLY REDUCED GRAPHENE OXIDE MODIFIED ELECTRODE
}

\author{
Birhanu Mekassa ${ }^{1}$, Priscilla G.L. Baker ${ }^{2}$, Bhagwan Singh Chandravanshi ${ }^{1 *}$ and Merid Tessema ${ }^{1}$ \\ ${ }^{1}$ Department of Chemistry, College of Natural Sciences, Addis Ababa University, P.O. Box \\ 1176, Addis Ababa, Ethiopia \\ ${ }^{2}$ Department of Chemistry, University of the Western Cape, Private Bag X17, Robert Sobukwe \\ Drive, Bellville, 7535, South Africa
}

(Received March 18, 2019; Revised July 2, 2019; Accepted July 3, 2019)

\begin{abstract}
This paper describes the application of nickel nanoparticles decorated electrochemically reduced graphene oxide modified glassy carbon electrode (NiNPs/ERGO/GCE) for the determination of ethambutol (ETB), an anti-Mycobacterium tuberculosis drug. The modified electrode showed remarkable electrocatalytic properties accompanied with a significant enhancement in the peak current response towards ETB compared to the bare electrode. The results showed that the composite modified electrode played a significant catalytic role due to the synergetic effect of NiNPs and ERGO. The NiNPs/ERGO modified electrode demonstrated excellent square wave voltammetric response towards ETB determination at the NiNPs/ERGO/GCE in the range $0.05-100 \mu \mathrm{M}$. The sensor demonstrated outstanding sensitivity towards ETB determination with limit of detection (LOD) and limit of quantification (LOQ) of 0.023 and $0.075 \mu \mathrm{M}$, respectively. The developed sensor was effectively validated for real sample study using drug formulation and urine samples which showed an acceptable recovery (99.6-109\%). The electrode also exhibited good precision $(\mathrm{RSD}<1 \%, \mathrm{n}=20)$, reproducibility $(\mathrm{RSD}<1.9 \%, \mathrm{n}=$ 3 ), long-term stability ( $92 \%$ of its initial response after two weeks) and selectivity towards interfering substances in the determination of ethambutol.
\end{abstract}

KEY WORDS: Ethambutol, Glassy carbon electrode, Square wave voltammetry, Electrochemically reduced graphene oxide, Nickel nanoparticles

\section{INTRODUCTION}

Tuberculosis (TB), caused by Mycobacterium tuberculosis (MB-TB), remains one of the most common infectious diseases of a major public health concern $[1,2]$. According to global WHO report of 2017, TB is the ninth leading cause of death worldwide and the primary cause from a single infectious agent, with 10.4 million cases and 1.674 million deaths in 2016 [3, 4]. The treatment of latent TB infection is usually done by a single antibiotic. However, the combinations of several antibiotics is used in the treatment of active TB therapy to reduce the risk of antibiotic resistance by the bacteria [5]. Ethambutol (ETB), together with pyrazinamide, isoniazid and rifampicin, are the first-line drugs for the treatment of tuberculosis $[2,6]$. ETB is a Mycobacterium-specific drug recommended for the treatment of the disease [5]. Nevertheless, continuous intake of antituberculosis drugs causes severe side effects. For example, an excess intake of isoniazid and pyrazinamide causes hepatic failure, leading to a fatal condition due to the excess formation of hydrazine during the isoniazid metabolism. Likewise, continuous use of ETB causes ophthalmic problems [7]. In contrast to rifampicin, isoniazid or pyrazinamide which are essentially eliminated by the liver, ETB is renally excreted, with two-thirds of the administered dose being recovered unchanged in urine. This leads to renal failure, which associate with significantly higher risks of toxicity, notably with retrobulbous optical nevritis [8]. In addition, as the TB drugs are used practically in higher doses for a longer period (6-9 months), continuous monitoring of the drug quality is crucial to reduce the risk of toxicity.

*Corresponding author. bscv2006@yahoo.com

This work is licensed under the Creative Commons Attribution 4.0 International License 
Therefore, it is very important to develop a simple, sensitive, reliable and environmentally friendly method for the determination of ethambutol. Several analytical techniques were reported including, potentiometry, Fourier-transform infrared spectroscopy, ultraviolet spectroscopy, fluorescence spectroscopy, capillary electrophoresis, supercritical fluid chromatography, mass spectrometry, high performance liquid chromatography and electroanalytical methods [5, 7, 9-13]. However, attention has been given to electrochemical techniques recently owing to their operational simplicity, sensitivity, cost effectiveness, absence of extensive sample pretreatment and suitability for onsite analysis due to their portability. Voltammetry based on chemically modified electrodes has got significant attention because of the possibility to tailor-made, control and design the electrode surface for the proposed application.

Nanocomposite modified electrodes based on graphene and metal nanoparticles are one of the most widely studied electrodes for electrochemical sensing. Graphene decorated with metal nanoparticles (MNPs) exhibited outstanding properties such as high electrocatalytic activity, excellent conductivity and selectivity $[14,15]$. The favorable behavior of the graphene supports may be attributed to the high dispersion of noble metals catalyst resulting from an improved interaction between functionalized graphene or graphene oxide (GO) surface and the noble metals nanoparticles and a large surface area of the graphene sheet support. In addition, abundant functional groups on the surfaces of GO can be used as anchoring sites for metal nanoparticles, which makes it possible to use them as a support to produce graphenenanoparticle hybrid nanostructures [16]. Furthermore, the incorporation of MNPs to highsurface-area materials like graphene provides enormous advantages for catalytic applications in terms of controlling the nucleation and growth of MNPs, which also prevents from aggregation and resulting in harvesting the synergistic effects of the MNPs and the supports [17].

This work focuses on the application of NiNPs/ERGO/GCE for the determination of ETB in pharmaceutical dosage forms and biological fluids, which is a continuation of our previous work [18]. In our previous report, we successfully constructed NiNPs/ERGO/GCE and used for the determination of diclofenac sodium which showed superior electrocatalytic behavior attributed to the higher available surface area, presence of impurities, higher intrinsic electrical conductivity, presence of special electronic structure and topological defects at the composite modified electrode compared to the bare glassy carbon electrode which facilitates the rate of electron transfer [18]. Therefore, the synthesis and characterization of NiNPs and GO, and the preparation of the electrode material, NiNPs/ERGO/GCE, is according to our previous paper [18].

\section{EXPERIMENTAL}

Chemicals, apparatus and instruments

All chemicals and reagents used were analytical grade. Ultrapure water from a Milli-pore Mill Q system was used for the preparations of all the solutions. Analytical grade chemicals and reagents were used as received without any additional purification in this work. Phosphate buffer solution (PBS) was prepared from sodium dihydrogen phosphate $\left(\mathrm{NaH}_{2} \mathrm{PO}_{4}\right)$ and disodium hydrogen phosphate $\left(\mathrm{Na}_{2} \mathrm{HPO}_{4}\right)$ (KIMIX Chemicals and Lab Supplies). Ethambutol dihydrochloride, isoniazid, acetaminophen (98\%), D-glucose, ascorbic acid, citric acid, urea, hydrochloric acid (37\%), and sodium hydroxide pellets (98\%) were from Sigma-Aldrich.

In all the experiments, a standard three electrode electrochemical cell with a bare or modified glassy carbon electrode (GCE, $3 \mathrm{~mm}$ in diameter) as the working electrode, a platinum wire as counter/auxiliary electrode and $\mathrm{Ag} / \mathrm{AgCl}(3 \mathrm{M} \mathrm{NaCl})$ as reference electrode. Alumina micropolish powder of varying sizes $(1,0.3$, and $0.05 \mu \mathrm{m})$ and polishing pads (Buehler) were used for electrode cleaning. All the electrochemical measurements were recorded with PalmSens Compact Electrochemical Interfaces (Palm Instruments BV, The Netherlands) 
interfaced to a computer and the results were reported with respect to $\mathrm{Ag} / \mathrm{AgCl}$. Electrochemical impedance spectroscopic experiments were performed on ZAHNER EIS machine (Germany) supported with THALES software.

\section{Preparation of $N i N P S / E R G O / G C E$}

The preparation procedure of the electrode, electrochemically reduced graphene oxide decorated with nickel nanoparticles modified electrode, NiNPs/ERGO/GCE, was adapted from our previous work [18]. Briefly, prior to the electrode modification, GCE was polished mechanically with $0.05,0.3$ and $1.0 \mu \mathrm{m}$ alumina slurry on a polishing cloth, rinsed thoroughly with ultrapure water. Then, the electrode was sonicated for 5 min each in ethanol and water in sequence using an ultrasonic cleaning bath to remove any physically adsorbed alumina particles. Following the ultrasonication, the electrode was rinsed with ultrapure water again and dried under infrared lamp.

\section{Real sample preparation}

For real sample analysis, rifafour e-275 tablet was obtained from a local pharmacy in Cape Town, South Africa. Rifafour is a drug that is used to treat tuberculosis and is a combination of four first line drugs: rifampicin $(150 \mathrm{mg})$, isoniazid $(75 \mathrm{mg})$, pyrazinamide $(400 \mathrm{mg})$ and ethambutol (275 mg), typically given at the early stages of tuberculosis. Five tablets of rifafour containing ethambutol as one of the active ingredient were finely powdered mixed and homogenized. Then, a weight equivalent to one tablet was weighed and dissolved in $250 \mathrm{~mL}$ ultrapure water by ultrasonication for $30 \mathrm{~min}$. After filtering twice using a Whatman filter paper, the solution was suitably diluted to get the final concentration in the linear range of the calibration curve. Human urine sample was obtained from healthy volunteer and filtered using the Whatman filter paper. $10 \mathrm{~mL}$ of the sample was then diluted in $100 \mathrm{~mL}$ volumetric flask using PBS pH 7 and analyzed without additional treatment.

\section{Analysis procedure and method validation}

The aim of this work was to apply a simple and sensitive NiNPs/ERGO/GCE hybrid modified electrode for an enhanced ethambutol detection, which offered an excellent electrochemical sensing platform. Optimization of experimental conditions for the detection of ethambutol is of critical importance. Hence, a systematic investigation of a number of variables related to CVs, such as $\mathrm{pH}$, scan rate and applied potential range were conducted. Cyclic voltammetric measurements were conducted from 0 to $1.6 \mathrm{~V}$ at a scan rate of $50 \mathrm{mV} \mathrm{s}^{-1}$ for $\mathrm{pH}$ optimization in $0.1 \mathrm{M}$ PBS in the $\mathrm{pH}$ ranges of 5.0-10. The scan rate studies were also conducted in the same range: 0 to $1.6 \mathrm{~V}$ at the composite modified electrode. For the construction of the calibration curve and quantification, square voltammetric measurements of ETB in the range of 0.5 to $1.5 \mathrm{~V}$ were used. Square wave parameters of $0.005 \mathrm{~V}$ of step potential, $0.05 \mathrm{~V}$ of amplitude and $25 \mathrm{~Hz}$ frequency were used following optimization.

The method validation for ethambutol determination was checked by performing recovery tests as well as evaluating the precision of the triplicate determinations. A satisfactory recovery result showed the successful determination of ethambutol without interfering agents in the real sample and that the ethambutol added has been detected. To make recovery measurements, a commercial rifafour tablet formulation and human urine real samples were spiked with different concentrations of standard ethambutol. The responses of the real samples (rifafour formulation and human urine samples) were first recorded before spiking. Then, the spiked samples were prepared by adding varying amounts of known concentration of standard ethambutol which was followed by recording the response of the square wave voltammetry. Then, the total ethambutol content was determined using the calibration curve and the recovery was calculated. 


\section{RESULTS AND DISCUSSION}

\section{Electrochemical behavior of ETB}

The electrochemical behavior of ethambutol was examined by cyclic voltammetry. As shown in Figure 1, no obvious redox peaks appeared for the buffer solution at the NiNPs/ERGO/GCE (curve a). However, a single oxidation peak was observed at the bare (b) and the modified glassy carbon electrodes (c-e) without any corresponding reduction peak in the reverse direction, indicating the irreversibility of the reaction of ethambutol at all the electrode surfaces. A weak oxidation peak of ETB appeared at a relatively higher potential region of about $1.2 \mathrm{~V}$ at the bare glassy carbon electrode (curve b). However, the peak current response of ethambutol was increased accompanied with a negative shift in peak potential at both nickel nanoparticles (curve c) and electrochemically reduced graphene oxide (curve d) modified electrodes. The observed result confirms further improvement in the electrochemical response of ETB at the composite modified electrode (NiNPs/ERGO/GCE) (curve e) with about 2.25 times increments in the peak current compared to the response of the bare electrode and a negative shift of the peak potential by nearly about $200 \mathrm{mV}$. This observation can be attributed to the increase in the surface area of the electrode and the catalytic role played by the nickel nanoparticles and electrochemically reduced graphene oxide with a synergetic effect. The use of ultrathin graphene nanosheets uniformly decorated with nickel nanoparticles hybrid material was reported for the simultaneous detection of sunset yellow and tartrazine food colorants which exhibited excellent accumulation and catalytic capacity, attributed to the large surface area and strong accumulation ability of graphene-nickel nanocomposite [19].

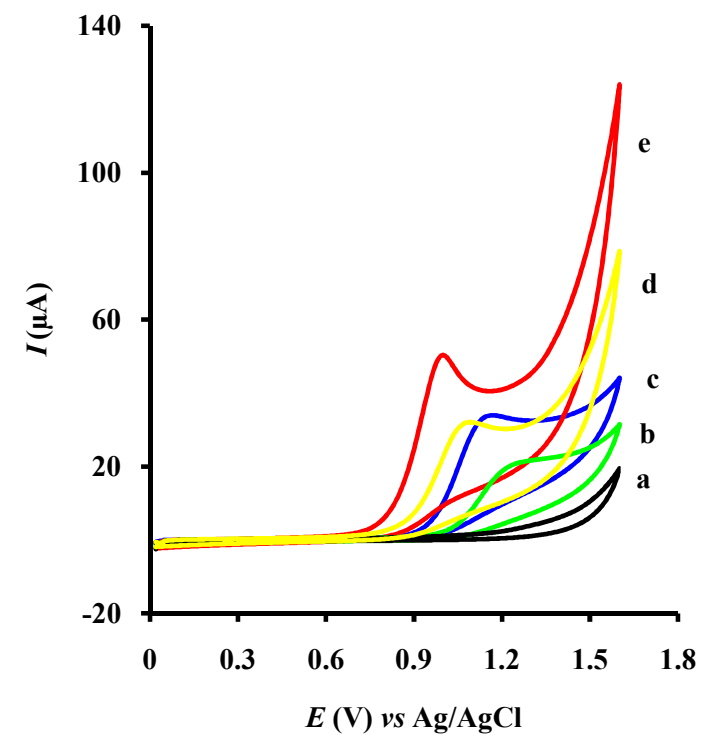

Figure 1. CVs recorded at bare GCE (b), NiNPs/GCE (c), ERGO/GCE (d) and NiNPs/ERGO/GCE $(a, e)$ in the absence (a) and presence (b-e) of $50 \mu \mathrm{M}$ ETB in $0.1 \mathrm{M}$ PBS $\mathrm{pH} 7$. 
Electrochemical impedance spectroscopy (EIS)

Electrochemical impedance spectroscopy (EIS) was employed to investigate the electrochemical characteristics of the bare and modified electrodes towards ETB detection. EIS measurement was carried out in $0.1 \mathrm{M}$ PBS containing $500 \mu \mathrm{M}$ ETB over a frequency range of $0.1 \mathrm{~Hz}$ to $10^{5}$ $\mathrm{Hz}$ with the AC signal amplitude of $10 \mathrm{mV}$, Figure 2. Generally, the Nyquist plot of the EIS is characterized by two important regions: a semicircular region at a higher frequency corresponding to the electron-transfer-limited process and a linear portion at low frequency region featuring diffusion limited process $[20,21]$. The diameter of the semicircular portion is equivalent to the charge transfer resistance $\left(R_{\mathrm{ct}}\right)$. The $R_{\mathrm{ct}}$ value obtained using the equivalent circuit fittings of the present study is in the order of: $42.9>24.5>13.7>12.2 \mathrm{k} \Omega$ for the unmodified GCE (a), NiNPs/GCE (b), ERGO/GCE (c) and NiNPs/ERGO/GCE (d), respectively. The smallest semicircle domain obtained at the NiNPs/ERGO modified GCE suggests that the nickel nanoparticles and graphene oxide composite promotes the electron transfer between ethambutol and the underlying electrode surface. The decrease in the diameter of the Nyquist plot at the composite compared to the individually modified electrode with nickel nanoparticles and graphene oxide further confirms the catalytic role played by each with synergistic effect. The result is in good agreement with the CV characterization.

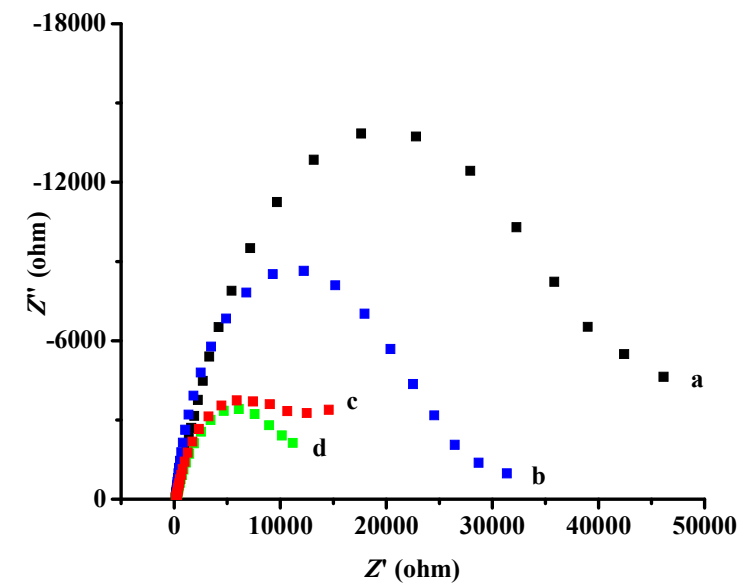

Figure 2. Nyquist Plot of EIS measured for $500 \mu \mathrm{M}$ ETB recorded at bare GCE (a), NiNPs/GCE (b), ERGO/GCE (c) and NiNPs/ERGO/GCE (d) in $0.1 \mathrm{M}$ PBS pH 7.

\section{Effect of potential scan rate}

In order to evaluate whether the electron transfer process of ETB at the composite modified electrode is diffusion or adsorption controlled, cyclic voltammetry was employed in the range of $10-500 \mathrm{mV} \mathrm{s}^{-1}$, Figure 3. The result showed that the peak current for $50 \mu \mathrm{M}$ ETB in $0.1 \mathrm{M}$ PBS pH 7 linearly increases with the square root of scan rates in the range of $10-500 \mathrm{mV} \mathrm{s}^{-1}$ with the linear regression equation of $I_{\mathrm{p}}(\mu \mathrm{A})=5.5( \pm 0.1) v^{1 / 2}\left(\mathrm{mV} \mathrm{s}^{-1}\right)^{1 / 2}+-2.8( \pm 1.5), R^{2}=0.9943$, Inset of Figure 3.This relationship suggests that the electrochemical reaction of ethambutol at the NiNPs/ERGO modified electrode is mainly diffusion-controlled electrode process [22-26]. The relationship between the logarithm of the peak current and the logarithm of the scan rate $\left(\log I_{\mathrm{p}}\right.$ $v s \log v)$ is also linear with the regression equation of $\log I_{\mathrm{p}}(\mu \mathrm{A})=0.56( \pm 0.02) \log v\left(\mathrm{mV} \mathrm{s}^{-1}\right)+$ $0.60( \pm 0.03), R^{2}=0.9903$. The slope value of 0.56 for the linear plot is very close to the theoretical value of 0.5 for diffusion controlled electrode process [27-29]. 


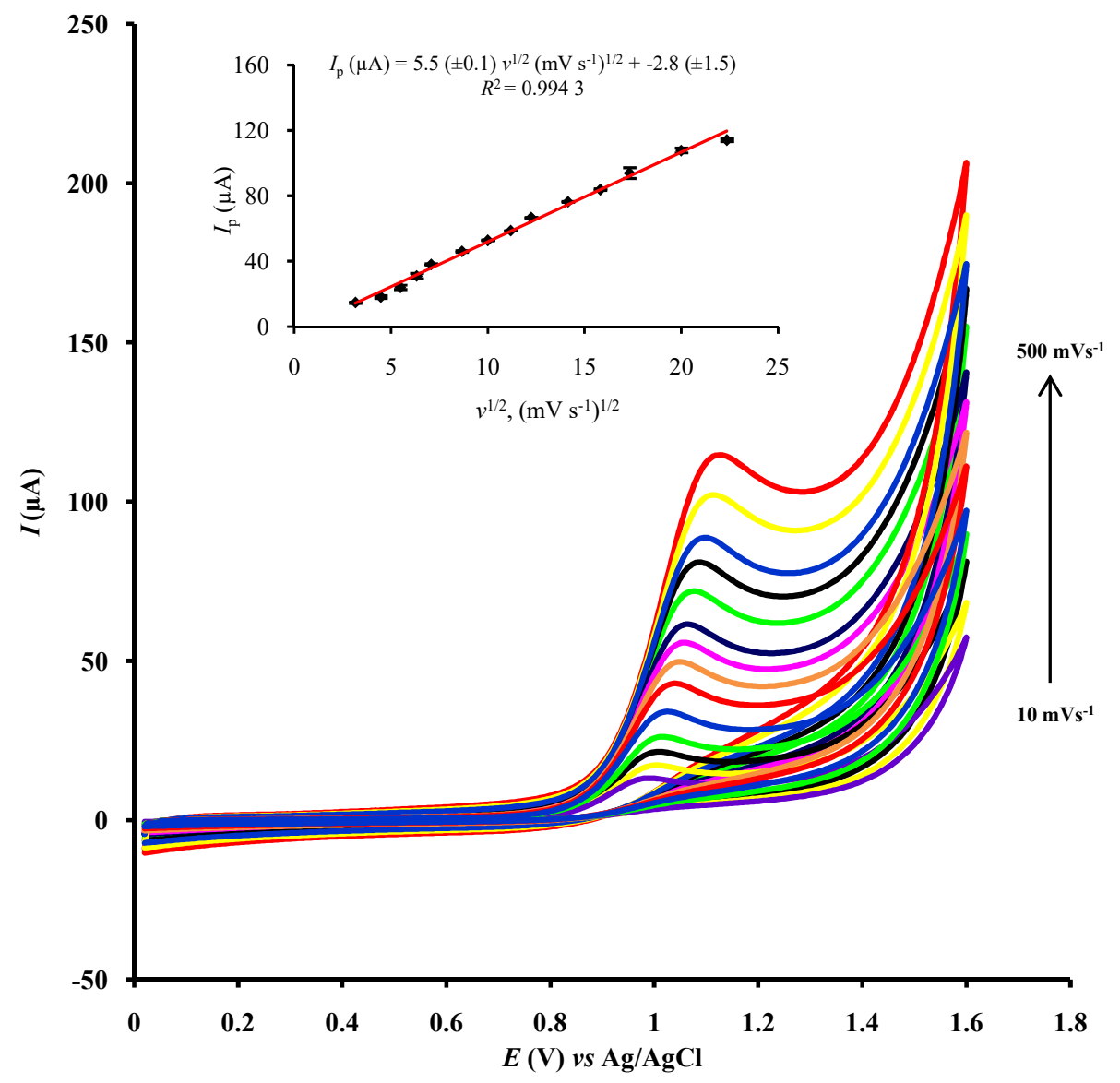

Figure 3. CVs recorded for $50 \mu \mathrm{M}$ ETB in PBS (pH 7) at NiNPs/ERGO/GCE at various scan rates $\left(100-500 \mathrm{mV} \mathrm{s}^{-1}\right)$. Inset: Plot of $I_{\mathrm{p}} v s v^{1 / 2}$ for $50 \mu \mathrm{M}$ ETB in PBS (pH 7) at NiNPs/ERGO/GCE.

The correlation between peak potential and scan rate was also investigated. It was observed that the oxidation peak potential depends on scan rate and gradually shifted to more positive values on increasing the scan rate, which confirms the irreversibility of the oxidation process of ethambutol at the electrode surface. According to Laviron's, for an irreversible electrode process the peak potential is defined by equation (1) $[28,30]$.

$$
E_{p}=E^{0^{\prime}}+\left(\frac{2.303 R T}{\alpha n F}\right) \log \left(\frac{R T k^{0}}{\alpha n F}\right)+\left(\frac{2.303 R T}{\alpha n F}\right) \log v
$$

where $E^{0^{\prime}}$ is the formal redox potential, $\mathrm{n}$ the number of electron transferred, $v$ the scan rate, $\alpha$ the transfer coefficient, $k^{0}$ the standard heterogeneous rate constant and the other symbols have their usual meanings. The relationship between the peak potential and the logarithm of the scan rate give a linear equation: $E_{\mathrm{p}}(\mathrm{V})=0.07( \pm 0.004) \log v+1.12( \pm 0.006), R^{2}=0.9622$. Hence, from the slope of $E_{\mathrm{p}} v s \log v$ in the above equation, the value of $\alpha$ can be calculated. The result 
was found to be 0.833 by taking $R=8.314 \mathrm{~J} \mathrm{~K}^{-1} \mathrm{~mol}^{-1}, T=298 \mathrm{~K}$ and $F=96480 \mathrm{C} \mathrm{mol}^{-1}$. According to Bard and Faulkner,[30] the transfer coefficient $\alpha$ is given by equation (2):

$$
\left|E_{\mathrm{p}}-E_{\mathrm{p} / 2}\right|=\frac{47.7}{\alpha} \mathrm{mV} \text { at } 25^{\circ} \mathrm{C}
$$

where $E_{\mathrm{p}} / 2$ is the potential where the current is at half of the peak value. Based on the above equation, the calculated $\alpha$ value is found to be 0.47 and the number of electrons transferred during the oxidation of ETB was estimated to be $1.8 \sim 2.0$.

\section{Effect of $\mathrm{pH}$}

The study of the influence of $\mathrm{pH}$ of the supporting electrolyte solution on the electrochemical response for $50 \mu \mathrm{M}$ ETB was examined in $0.1 \mathrm{M}$ PBS in the $\mathrm{pH}$ ranges of 5.0-10 using cyclic voltammetry. Figure 4 depicts the CVs of $50 \mu \mathrm{M}$ ETB at NiNPs/ERGO/GCE. The result showed that there is an increase in the oxidation peak current response of ETB as the $\mathrm{pH}$ increases from 5.0 to 7.0 and reaches a maximum value at $\mathrm{pH}$ 7. Further increase in the $\mathrm{pH}$ from 7 to 10 resulted in a gradual decrease of the peak current responses. Therefore, PBS of $\mathrm{pH} 7.0$ was employed as the optimum $\mathrm{pH}$ for the following analysis at NiNPs/ERGO/GCE. The effect of the $\mathrm{pH}$ of the buffer solution on the oxidation peak potential of ETB was also evaluated. It was found that the oxidation peak potential shifted negatively with increasing $\mathrm{pH}$ (Inset of Figure 4). The negative shift in the oxidation peak potential due to the change in $\mathrm{pH}$ from acidic to basic solution indicates proton participation in the oxidation process. The relationship between the anodic peak potentials and $\mathrm{pH}$ was linear with the regression equation: $E_{\mathrm{pa}}(\mathrm{V})=$ $-0.034( \pm 0.002) \mathrm{pH}+1.3( \pm 0.012), R^{2}=0.9910$. The slope of $-34 \mathrm{mV} / \mathrm{pH}$ is nearly half of the theoretical Nernstian slope of $59 \mathrm{mV} / \mathrm{pH}$. This indicates that the proportion of the electrons and protons involved in the oxidation reaction of ETB at NiNPs/ERGO/GCE are in 2:1 ratio. This is in agreement with previous reports [7].

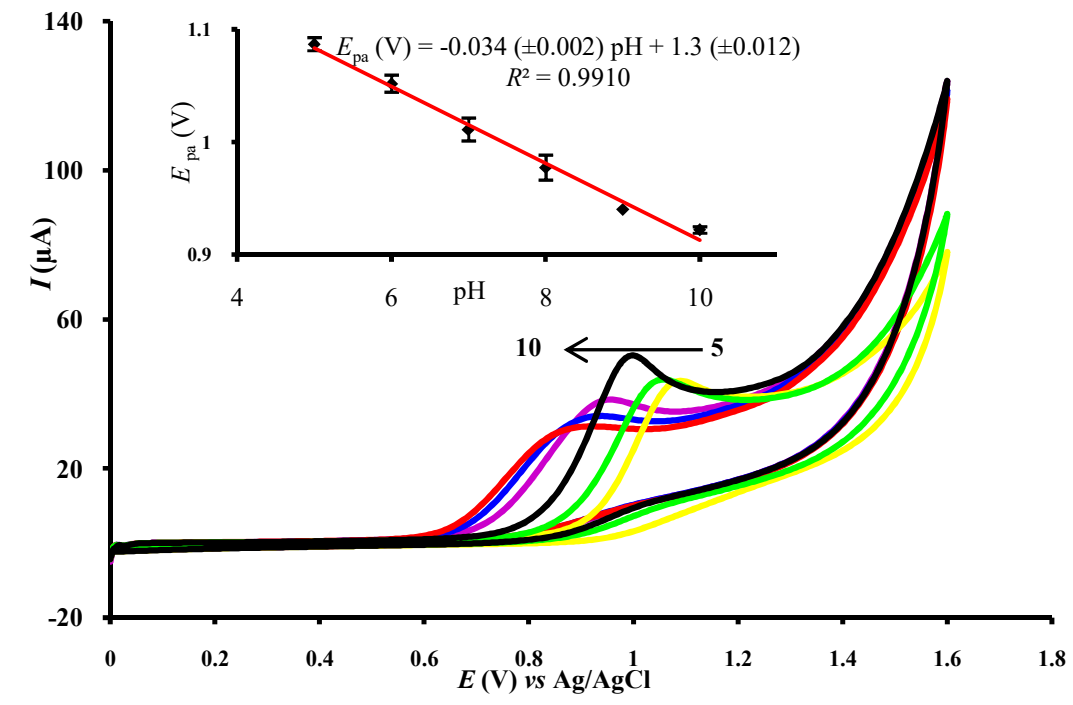

Figure 4. CVs of $50 \mu \mathrm{M}$ ETB recorded in $0.1 \mathrm{M}$ PBS of varying $\mathrm{pH}$ at NiNPs/ERGO/GCE. Inset: Peak potential $v s \mathrm{pH}$ for $50 \mu \mathrm{M}$ ETB at NiNPs/ERGO/GCE. 
Calibration curve

Due to its high sensitivity, square wave voltammetry was used to evaluate the relationship between peak current and concentrations of ethambutol. Under the optimal experimental conditions, the peak current response varied linearly with concentration of ETB in range of $0.05-100 \mu \mathrm{M}$ with a linear regression equation of $I_{\mathrm{p}}(\mu \mathrm{A})=0.4( \pm 0.005)$ [ETB] $(\mu \mathrm{M})+1.7$ $( \pm 0.228), R^{2}=0.9984$, Figure 5 and 6 . The limit of detection $(S / N=3)$ and limit of quantification $(S / N=10)$ were found to be 0.023 and $0.075 \mu \mathrm{M}$, respectively. The analytical performance evaluation of the present method was compared with other similar electrochemical methods reported in the literature for the determination ETB which is summarized in Table 1. The obtained summary confirmed that the present sensor exhibited a superior performance than the previously reported electrochemical methods in terms of achieving lower limit of detection and acceptable linear dynamic range.

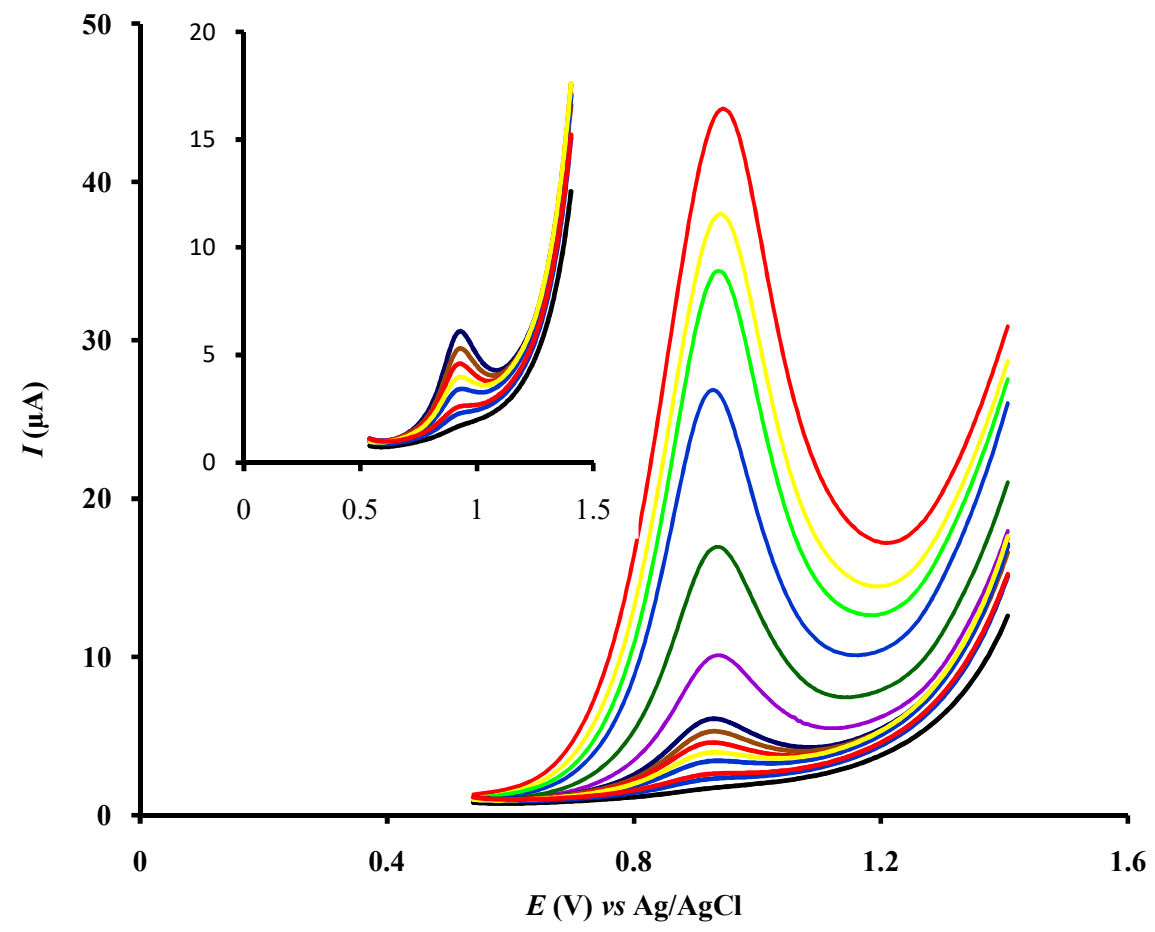

Figure 5. SWVs at NiNPs/ERGO/GCE in $0.1 \mathrm{M} \mathrm{PBS} \mathrm{pH} 7$ for different concentrations of ETB: $0,0.05,2,4,6,8,10,12,20,40,60,75,90$ and $100 \mu \mathrm{M}$. Inset: magnified CV curve for lower concentrations $(0-12 \mu \mathrm{M})$. 


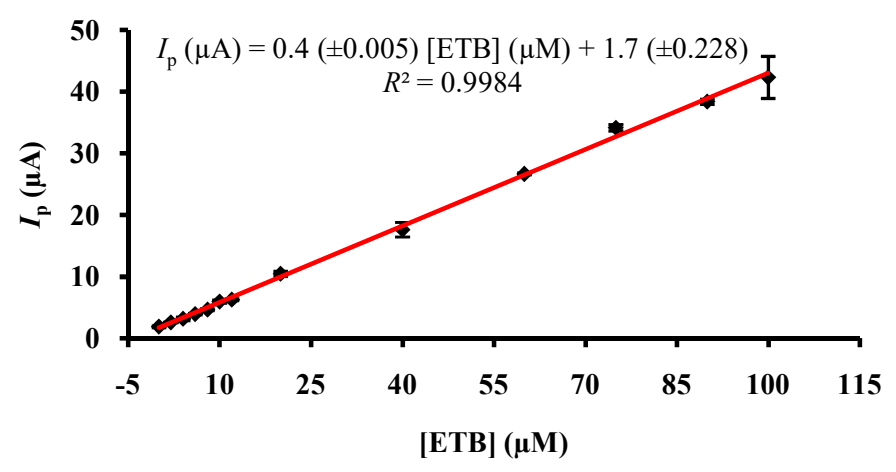

Figure 6. Calibration plot of peak current vs concentration of ETB at NiNPs/ERGO/GCE.

Table 1. Comparison of the analytical performance of the NiNPs/ERGO/GCE with other electrodes previously reported in the literature for the determination of ETB.

\begin{tabular}{|l|c|c|c|c|}
\hline Electrode type & Technique & $\begin{array}{c}\text { Linear range } \\
(\mu \mathrm{M})\end{array}$ & LOD $(\mu \mathrm{M})$ & {$[\mathrm{Ref}]$.} \\
\hline $\begin{array}{l}\text { Graphite-paraffin composite } \\
\text { electrode }\end{array}$ & Amperometric & $250-1500$ & 100 & {$[32]$} \\
\hline $\begin{array}{l}\text { Graphite-polyurethane } \\
\text { composite electrode }\end{array}$ & Amperometric & $500-1100$ & 63.4 & {$[33]$} \\
\hline Gold microelectrode array & Amperometric & $50-2000$ & 0.155 & {$[34]$} \\
\hline${ }^{\mathrm{a} A u / P V P-A g-P A N S A / C Y P 2 E 1 ~}$ & Chronoamperometric & $2-12$ & 0.7 & {$[35]$} \\
\hline Nafion/MWCNT/SPCEs & SWV & $1.4 \times 10^{5}-1.4 \times 10^{6}$ & 4000 & {$[36]$} \\
\hline Tyrosine/GCE & DPV & $20-100$ & 9.61 & {$[37]$} \\
\hline MWCNT/GCE & DPV & $8-2500$ & 0.76 & {$[38]$} \\
\hline${ }^{b} P_{M e l}-A u_{n a n} / G C E$ & DPV & $0.5-150$ & 0.21 & {$[39]$} \\
\hline NiNPs/ERGO/GCE & SWV & $0.05-100$ & 0.023 & {$[$ This work] } \\
\hline
\end{tabular}

${ }^{a}$ cytochrome $\mathrm{C}$ immobilised on poly(8-anilino-1-napthalene sulphonic acid) and silver nanoparticles stabilized in polyvinylpyrrolidone (PVP) modified gold electrode, ${ }^{b}$ poly-melamine/electrodeposited gold nanoparticles modified pre-anodized GCE.

\section{Repeatability, reproducibility and stability}

The precision of the method was evaluated as a degree of repeatability by measuring the square wave voltammetric response of $50 \mu \mathrm{M}$ ETB. Figure 7a depicts the SWVs recorded for $50 \mu \mathrm{M}$ ETB for twenty consecutive measurements for the same electrode. The $\% R S D$ of the maximum peak currents recorded for the same electrode for twenty successive measurements was found to be $1.0 \%(n=20)$, indicating an outstanding precision of the modified electrode. The reproducibility of the sensor was assessed by comparing the responses of three NiNPs/ERGO/GCE electrodes independently prepared under similar experimental conditions. The relative standard deviation $(R S D)$ of the current responses was $1.9 \%$ for $n=3$. The longterm stability of this sensor was also tested. The electrode was placed at ambient temperature when not in use. The oxidation current response for $50 \mu \mathrm{M}$ ETB was measured by SWV for the same electrode every day for two weeks. The current response was only slightly reduced after two weeks and maintains greater than $92 \%$ of its initial response. In general, the developed sensor demonstrated excellent results in terms of repeatability, reproducibility, and long-term stability towards ethambutol determination. 
Analytical application

The feasibility and reliability of the proposed method for practical application was evaluated by analyzing commercial pharmaceutical tablet of Rifafour containing ethambutol and human urine. The procedure followed for sample preparation is described in experimental section. Square wave voltammetric measurements were carried out in triplicate and the standard addition method was employed to quantify the amount of ethambutol present. In addition, the accuracy of the method was tested by spiking the real sample with known concentrations of standard solutions and calculating the recovery values. The results are summarized in Table 2 . The amount of ethambutol determined is in close agreement with the specified amounts in the drug information leaflet and the recovery results for both real samples are also very good. Moreover, the other drugs present in the Rifafour formulation did not interfere with the determination of ethambutol. The SWV response of Rifafour in PBS pH 7 in the potential window of $-0.2 \mathrm{~V}$ to 1.6 V, showed two peaks: the first one attributed to isoniazid and the second peak for ethambutol. Uric acid was detected at about $0.3 \mathrm{~V}$ in the urine samples analyzed but did not interfere with the determination of ethambutol. Figure $7 \mathrm{~b}$ shows the SWVs of the urine sample before (a) and after spiking (b-h) with different concentrations of ETB.

Table 2. Determination of ETB in Rifafour tablet formulation and human urine samples and the recovery results at $\mathrm{NiNPs} / \mathrm{ERGO} / \mathrm{GCE}$ using SWV.

\begin{tabular}{|c|c|c|c|c|c|}
\hline $\begin{array}{l}\text { Real } \\
\text { sample }\end{array}$ & $\begin{array}{l}\text { Specified } \\
\text { content (mg) }\end{array}$ & $\begin{array}{l}\text { Determined } \\
(\mathrm{mg})\end{array}$ & $\begin{array}{c}\text { Added } \\
(\mu \mathrm{M})\end{array}$ & $\begin{array}{l}{ }^{a} \text { Found } \pm R S D \\
(\mu \mathrm{M})\end{array}$ & $\begin{array}{c}\text { Recovery } \\
(\%)\end{array}$ \\
\hline \multirow[t]{6}{*}{ Rifafour } & \multirow[t]{6}{*}{275} & \multirow[t]{6}{*}{$267 \pm 5$} & 0 & $15.4 \pm 0.6$ & - \\
\hline & & & 15 & $32.3 \pm 1.4$ & 106 \\
\hline & & & 50 & $65.7 \pm 1.4$ & 101 \\
\hline & & & 0 & $8.0 \pm 2.5$ & - \\
\hline & & & 20 & $27.9 \pm 1.8$ & 99.6 \\
\hline & & & 50 & $58.0 \pm 0.9$ & 100 \\
\hline \multirow[t]{4}{*}{ Urine } & \multirow[t]{4}{*}{ - } & \multirow[t]{4}{*}{ - } & 0 & - & - \\
\hline & & & 15 & $15.6 \pm 5.4$ & 104 \\
\hline & & & 40 & $43.7 \pm 2.2$ & 109 \\
\hline & & & 75 & $74.8 \pm 1.2$ & 99.7 \\
\hline
\end{tabular}

${ }^{a}$ Mean value $(n=3)$.

\section{Effect of interferences}

In order to evaluate the potential analytical application of the proposed method, the interference effect of some common inorganic and organic substances that might coexist in pharmaceutical formulation and/or biological fluids were examined. The tolerance limit was defined as the maximum amount of the potentially interfering substances that caused an error of less than $5 \%$ in the determination of ethambutol. The effect of these interfering compounds on the square wave voltammetric response was studied by measuring the response for a solution containing a fixed amount of ethambutol $(50 \mu \mathrm{M})$ spiked with varying concentrations of the interferents under the same experimental conditions. The results are presented in Table 3, which shows the selectivity of the method towards ethambutol detection. The CVs recorded for $50 \mu \mathrm{M}$ ETB before and after addition of $50 \mu \mathrm{M}$ of isoniazid (ISZ), L-ascorbic acid (AA) and acetaminophen (ACP) at NiNPs/ERGO/GCE at $50 \mathrm{mV} \mathrm{s}^{-1}$ suggested the possibility of simultaneous determination of these substances with ethambutol without any interference effect. 

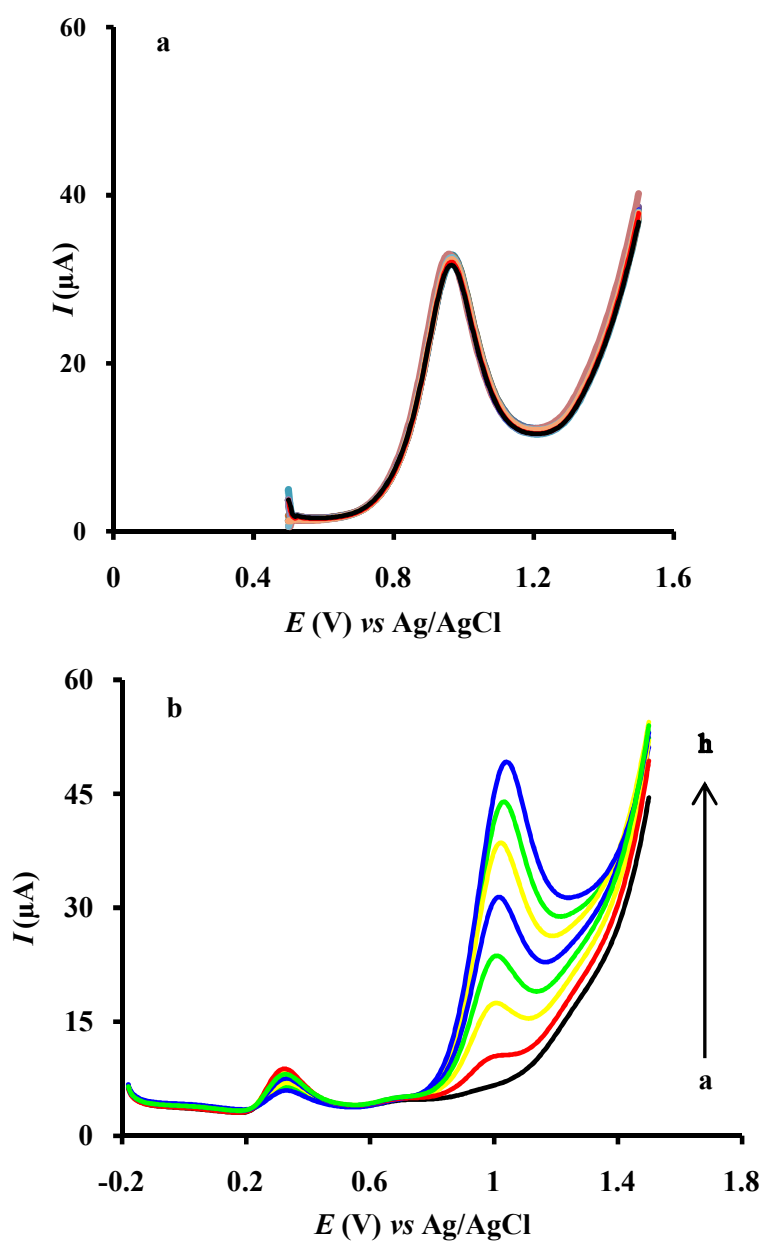

Figure 7. (a) SWVs recorded for $50 \mu \mathrm{M}$ ETB for twenty consecutive measurements; (b) SWVs of the urine sample after spiking with different concentrations of ETB $(\mathrm{a} \rightarrow \mathrm{h}: 0,15,30$, $40,60,70,90,100 \mu \mathrm{M})$.

Table 3. Effect of potential interfering substances on the peak current of $50 \mu \mathrm{M}$ ETB at NiNPs/ERGO/GCE, $(n=3)$.

\begin{tabular}{|l|c|c|}
\hline Interferents & Concentration $(\mu \mathrm{M})$ & Signal change (\%) \\
\hline $\mathrm{Ca}^{2+}, \mathrm{Mg}^{2+}, \mathrm{K}^{+}, \mathrm{SO}_{4}{ }^{2-}, \mathrm{CO}_{3}{ }^{2-}, \mathrm{Cl}^{-1}$ & 10000 & -0.91 \\
\hline $\mathrm{L}$-Ascorbic acid & 10000 & -1.0 \\
\hline Glucose & 6600 & 4.3 \\
\hline Urea & 6600 & -1.8 \\
\hline Citric acid & 3000 & 2.0 \\
\hline Isoniazid & 3000 & -2.9 \\
\hline Acetaminophen & 800 & 2.2 \\
\hline
\end{tabular}

Bull. Chem. Soc. Ethiop. 2019, 33(2) 


\section{CONCLUSION}

This work demonstrates the application of NiNPs/ERGO/composite modified glassy carbon electrode for a sensitive square wave voltammetric determination of ethambutol. The electrode was successfully prepared by a single step electrodeposition method in PBS (pH 7). The electrode showed remarkable sensitivity to the determination of ethambutol as compared to the bare and the individual NiNPs or ERGO modified glassy carbon electrode owing to the synergetic effect between the NiNPs and ERGO. The application of electrochemically reduced graphene oxide decorated with nickel nanoparticles for ETB improved the electron transfer process between the analyte and the underlying electrode which can be ascribed to the electrocatalytic activity of the nanomaterials and improved surface area of the electrode. The modified electrode exhibited outstanding response towards ETB in terms achieving wide linear range $(0.05-100 \mu \mathrm{M})$ and lower limit of detection $(0.023 \mu \mathrm{M})$. This is the highest sensitivity reported for ETB so far, for voltammetric methods based on chemical sensors. The $\mathrm{NiNP} / \mathrm{ERGO} / \mathrm{GCE}$ was also effectively used for ethambutol determination in real samples with good recovery. Thus, it is a potential candidate for electrochemical determination of ETB and related drugs as well as biologically active compounds in real samples.

\section{ACKNOWLEDGEMENTS}

The authors greatly appreciate the support from the University of the Western Cape, Department of Chemistry, Cape Town, South Africa.

\section{REFERENCES}

1. Zumla, A.; Nahid, P.; Cole, S.T. Advances in the development of new tuberculosis drugs and treatment regimens. Nat. Rev. Drug Discov. 2013, 12, 388-404.

2. Gong, Z.; Basir, Y.; Chu, D.; McCort-Tipton, M. A rapid and robust liquid chromatography/tandem mass spectrometry method for simultaneous analysis of antituberculosis drugs - ethambutol and pyrazinamide in human plasma. J. Chromatogr. B 2009, 877, 1698-1704.

3. World Health Organization Global Tuberculosis Report 2017. Geneva: World Health Organization; 2017; Licence: CC BY-NCSA 30 IGO; Switzerland; 2017, pp 1-249.

4. Wallis, R.S.; Maeurer, M.; Mwaba, P.; Chakaya, J.; Rustomjee, R.; Migliori, G.B.; Marais, B.; Schito, M.; Churchyard, G.; Swaminathan, S.; Hoelscher, M.; Zumla, A. Tuberculosisadvances in development of new drugs, treatment regimens, host-directed therapies, and biomarkers. Lancet Infect. Dis. 2016, 16, 34-46.

5. Sepehri, Z.; Bagheri, H.; Ranjbari, E.; Amiri-Aref, M.; Amidi, S.; Rouini, M.R.; Ardakani, Y.H. Simultaneous electrochemical determination of isoniazid and ethambutol using polymelamine/electrodeposited gold nanoparticles modified pre-anodized glassy carbon electrode. Ionics 2017, 24, 1253-1263.

6. Ferraz, B.R.; Leite, F.R.; Malagutti, A.R. Simultaneous determination of ethionamide and pyrazinamide using poly(L-cysteine) film-modified glassy carbon electrode. Talanta 2016, 154, 197-207.

7. Cheemalapati, S.; Devadas, B.; Chen, S-M.; Ali, M.A.; Al-Hemaid, F.M.A. Electrochemical determination of selected antihypertensive and antituberculosis drugs at a tyrosine-modified electrode. Anal. Methods 2014, 6, 6774-6782.

8. Chenevier, P.; Massias, L.; Gueylard, D.; Farinotti, R. Determination of ethambutol in plasma by high-performance liquid chromatography after pre-column derivatization. $J$. Chromatogr. B 1998, 708, 310-315. 
9. Perantoni C.B.; Carbogim, L.G.S.; Semaan F.S.; Matos R.C.; Lowinsohn, D. Flow injection analysis of ethambutol in antituberculosis drugs using a graphite-paraffin electrode as amperometric detector. Electroanalysis 2011, 23, 2582-2585.

10. Lima, A.E.B.; Luz, G.E.; Batista, N.C.; Longo, E.; Cavalcante, L.S.; Santos, R.S. Determination of ethambutol in aqueous medium using an inexpensive gold microelectrode array as amperometric sensor. Electroanalysis 2016, 28, 985-989.

11. Ngece, R.F.; West, N.; Ndangili, P.M.; Olowu R.A.; Williams, A.; Hendricks, N.; Mailu, S.; Baker, P.; Iwuoha, E. A silver nanoparticle/poly (8-anilino-1-naphthalene sulphonic acid) bioelectrochemical biosensor system for the analytical determination of ethambutol. Int. J. Electrochem. Sci. 2011, 6, 1820-1834.

12. Couto, R.A.; Quinaz, M.B. Development of a Nafion/MWCNT-SPCE-based portable sensor for the voltammetric analysis of the anti-tuberculosis drug ethambutol. Sensors 2016, 16, 1015-1027.

13. Prajapati, P.; Agrawal, Y.K. SFC-MS for the identification and estimation of ethambutol in its dosage form and in human urine samples. Anal. Methods 2016, 8, 4895-4902.

14. Gutes, A.; Hsia, B.; Sussman, A.; Mickelson, W.; Zettl, A.; Carraro, C.; Maboudian, R. Graphene decoration with metal nanoparticles: towards easy integration for sensing applications. Nanoscale 2012, 4, 438-440.

15. Pandikumar, A.; How, G.T.S.; See, T.P.; Omar, F.S.; Jayabal, S.; Kamali, K.Z.; Yusoff, N.; Jamil, A.; Ramaraj, R.; John, S.A.; Lim, H.N.; Huang, N.M. Graphene and its nanocomposite material based electrochemical sensor platform for dopamine. RSC $A d v$. 2014, 4, 63296-63323.

16. Ioni, Y.; Buslaeva, E.; Gubin, S. Synthesis of graphene with noble metals nanoparticles on its Surface. Mater. Today: Proceed. 2016, 3, 209-213.

17. Zhu, Q-L.; Xu, Q. Immobilization of ultrafine metal nanoparticles to high-surface-area materials and their catalytic applications. Chem. 2016, 1, 220-245.

18. Mekassa, B.; Baker, P.G.L.; Chandravanshi, B.S.; Tessema, M. Synthesis, characterization, and preparation of nickel nanoparticles decorated electrochemically reduced graphene oxide modified electrode for electrochemical sensing of diclofenac. J. Solid State Electrochem. 2018, 22, 3607-3619.

19. Gan, T.; Sun, J.; Wu, Q.; Jing, Q.; Yu, S. Graphene decorated with nickel nanoparticles as a sensitive substrate for simultaneous determination of sunset yellow and tartrazine in food samples. Electroanalysis 2013, 25, 1505-1512.

20. Li, X.; Zhong, A.; Wei, S.; Luo, X.; Liang, Y.; Zhu, Q. Polyelectrolyte functionalized gold nanoparticles-reduced graphene oxide nanohybrid for electrochemical determination of aminophenol isomers. Electrochim. Acta 2015, 164, 203-210.

21. Gan, T.; Wang, Z.; Wang, Y.; Li, X.; Sun, J.; Liu, Y. Flexible graphene oxide-wrapped $\mathrm{SnO}_{2}$ hollow spheres with high electrochemical sensing performance in simultaneous determination of 4-aminophenol and 4-chlorophenol. Electrochim. Acta 2017, 250, 1-9.

22. Asadpour-Zeynali, K.; Mollarasouli, F. Novel electrochemical biosensor based on PVP capped $\mathrm{CoFe}_{2} \mathrm{O}_{4} @ \mathrm{CdSe}$ core-shell nanoparticles modified electrode for ultra-trace level determination of rifampicin by square wave adsorptive stripping voltammetry. Biosens. Bioelectron. 2017, 92, 509-516.

23. Zhao, Z.; Xia, Z.; Liu, C.; Huang, H.; Ye, W. Green synthesis of $\mathrm{Pd} / \mathrm{Fe}_{3} \mathrm{O}_{4}$ composite based on polyDOPA functionalized reduced graphene oxide for electrochemical detection of nitrite in cured food. Electrochim. Acta 2017, 256, 146-154.

24. Kaur, B.; Srivastava, R. Simultaneous electrochemical determination of nanomolar concentrations of aminophenol isomers using nanocrystalline zirconosilicate modified carbon paste electrode. Electrochim. Acta 2014, 141, 61-71. 
25. Yi, W.; Yang, D.; Chen, H.; Liu, P.; Tan, J.; Li, H. A highly sensitive nonenzymatic glucose sensor based on nickel oxide-carbon nanotube hybrid nanobelts. J. Solid State Electrochem. 2013, 18, 899-908.

26. Khamlichi, R.E.; Bouchta, D.; Atia, M.B.; Choukairi, M.; Khalid, R.T.; Raissouni, I.; Tazi, S.; Mohammadi, A.; Soussi, A.; Draoui, K.; Faiza, C.; Sefian, M.L. A novel carbon/chitosan paste electrode for electrochemical detection of normetanephrine in the urine. J. Solid State Electrochem. 2018, 22, 1983-1994.

27. Gorla, F.A.; Duarte, E.H.; Sartori, E.R.; Tarley, C.R.T. Electrochemical study for the simultaneous determination of phenolic compounds and emerging pollutant using an electroanalytical sensing system based on carbon nanotubes/surfactant and multivariate approach in the optimization. Microchem. J. 2016, 124, 65-75.

28. Gowda, J.I.; Nandibewoor, S.T. Electrochemical behavior of paclitaxel and its determination at glassy carbon electrode. Asian J. Pharm. Sci. 2014, 9, 42-49.

29. Jafarian, M.; Forouzandeh, F.; Danaee, I.; Gobal, F.; Mahjani, M.G. Electrocatalytic oxidation of glucose on $\mathrm{Ni}$ and $\mathrm{NiCu}$ alloy modified glassy carbon electrode. J. Solid State Electrochem. 2008, 13, 1171-1179.

30. Lavron, E. General expression of the linear potential sweep voltammogram in the case of diffusionless electrochemical systems. J. Electroanal. Chem. 1979, 101, 19-28.

31. Bard, A.J.; Faulkner, L.R. Electrochemical Methods Fundamentals and Applications, Wiley: New York; 2001; $\mathrm{p} 236$.

32. Aguilar-Lira, G.Y.; Álvarez-Romero, G.A.; Zamora-Suárez, A.; Palomar-Pardavé, M.; Rojas-Hernández, A.; Rodríguez-Ávila, J.A.; Páez-Hernández, M.E. New insights on diclofenac electrochemistry using graphite as working electrode. J. Electroanal. Chem. 2017, 794, 182-188.

33. Karuppiah, C.; Cheemalapati, S.; Chen, S-M.; Palanisamy, S. Carboxyl-functionalized graphene oxide-modified electrode for the electrochemical determination of nonsteroidal anti-inflammatory drug diclofenac. Ionics 2015, 21, 231-238.

34. Goyal, R.N.; Chatterjee, S.; Agrawal, B. Electrochemical investigations of diclofenac at edge plane pyrolytic graphite electrode and its determination in human urine. Sens. Actuator. B Chem. 2010, 145, 743-748.

35. Shalauddin, M.; Akhter, S.; Bagheri, S.; Karim, M.S.A.; Kadri, N.A.; Basirun, W.J. Immobilized copper ions on MWCNTS-Chitosan thin film: Enhanced amperometric sensor for electrochemical determination of diclofenac sodium in aqueous solution. Int. $J$. Hydrogen Energy 2017, 42, 19951-19960.

36. Chethana, B.K.; Basavanna, S.; Naik, Y.A. Voltammetric determination of diclofenac sodium using tyrosine modified carbon paste electrode. Ind. Eng. Chem. Res. 2012, 51, 10287-10295.

37. Goyal, R.N.; Chatterjee, S.; Rana, A.R.S. The effect of modifying an edge-plane pyrolytic graphite electrode with single-wall carbon nanotubes on its use for sensing diclofenac. Carbon 2010, 48, 4136-4144.

38. Sarhangzadeh, K.; Khatami, A.A.; Jabbari, M.; Bahari, S. Simultaneous determination of diclofenac and indomethacin using a sensitive electrochemical sensor based on multiwalled carbon nanotube and ionic liquid nanocomposite. J. Appl. Electrochem. 2013, 43, 12171224.

39. Afkhami, A.; Bahiraei, A.; Madrakian, T. Gold nanoparticle/multi-walled carbon nanotube modified glassy carbon electrode as a sensitive voltammetric sensor for the determination of diclofenac sodium. Mater. Sci. Eng. C 2016, 59, 168-176. 